\title{
Utilising Grape Pomace for Ethanol Production
}

\author{
L.J. Korkie ${ }^{1}$, B.J.H. Janse ${ }^{2}$ and M. Viljoen-Bloom ${ }^{1}$
}

1) Department of Microbiology, Stellenbosch University, Private Bag X1, 7602 Matieland (Stellenbosch), South Africa

2) Mondi Forests, PO Box 12, Hilton, 3245, South Africa

Submitted for publication: December 2001

Accepted for publication: April 2002

Key words: Ethanol, grape pomace, bioprocessing

\begin{abstract}
Chemical analyses of grape pomace revealed the presence of significant amounts of fermentable sugars that are retained in the pomace after pressing of the grapes. Furthermore, treatment of the pomace with purified hydrolases indicated that the enzymatic biodegradation of the pomace could release additional fermentable sugars. We isolated and evaluated yeast strains associated with grape pomace for their ability to hydrolyse the complex polysaccharides found in grape pomace and to utilise the fermentable sugars for the production of ethanol. Two Pichia rhodanensis isolates were able to partially hydrolyse the pomace polysaccharides, but fermentation of the pomace resulted only in a small increase in the amount of ethanol produced. The study revealed that significant amounts of ethanol could be obtained from the residual sugars associated with grape pomace. However, the complex structure of the pomace polysaccharides apparently renders it unsusceptible to efficient hydrolysis under fermentative conditions.
\end{abstract}

Grape pomace is the fibrous material that remains after the juice has been extracted from grape berries and consists of processed skins, seeds and stems (Hang, 1988; Mazza, 1995). During the production of wine the grape pomace is separated from the grape juice prior to the fermentation of white wines, or after a few days of skin contact in red wines (Prescott et al., 1993). As large amounts of pomace are produced annually by the wine industry, the possible environmental impact of grape pomace is a growing concern (Mazza, 1995; Greene, 1998). Grape pomace is considered to be a waste product with little economic value. It is potentially useful as an animal feed and the seed extracts provide grape seed oil for health food and gourmet groceries (Amerine et al., 1972; Valiente et al., 1995; Heimoff, 1996; Greene, 1998). Pomace can also be ploughed back into vineyard soils as a natural source of nitrogen and phosphate, or to provide nutrients in a concentrated and stable form (Greene, 1998). However, the high moisture content and residual levels of sucrose, glucose, fructose and traces of other reducing sugars present in grape pomace, render it susceptible to rapid microbial spoilage (Hang, 1988).

The carbohydrate fractions of grape pomace are a potential source of fermentable sugars that are of commercial interest to the wine industry. Grape pomace consists of the four major polysaccharides in nature, namely cellulose (consisting of glucose subunits), hemicellulose (glucose, mannose, xylan and arabinose subunits), starch (glucose subunits) and pectin (D-galacturonic acid subunits) (Hulme, 1970). Starch serves mainly as an energy reserve in plants, while cellulose, hemicellulose and pectin are closely associated in an integrated structure to support the cell wall (Glazer \& Nikaido, 1995).

The polysaccharides in grape pomace should be at least partially degraded to release mono- and disaccharides that can be utilised or fermented by yeasts. The wine yeast Saccharomyces cerevisiae is well known for its ability to produce ethanol from various fermentable sugars, but it lacks the essential hydrolases required to degrade complex polysaccharides (Glazer \& Nikaido, 1995). A number of hydrolase genes were previously expressed in S. cerevisiae to enable the yeast to degrade purified cellulose or glucan (Petersen et al., 1998; Van Rensburg et al., 1998). In this study naturally occurring micro-organisms were isolated from grape pomace and evaluated for their ability to hydrolyse purified polysaccharides and those present in grape pomace. Potential yeast candidates were further evaluated for the production of ethanol under fermentative conditions.

\section{MATERIALS AND METHODS}

\section{HPLC analysis of hydrolysed pomace}

A mixture of pressed red and white grape pomace was obtained from a Stellenbosch winery (Stellenbosch, South Africa), dried at $60^{\circ} \mathrm{C}$ for $48 \mathrm{~h}$, grounded with a household coffee grinder to reduce the particular size and obtain a homogenous mixture, and autoclaved for $15 \mathrm{~min}$. For acid hydrolysis a $15 \%$ (w/v) suspension of the dried pomace was made in $\mathrm{ddH}_{2} \mathrm{O}$ and hydrolysed with $12 \mathrm{M}$ $\mathrm{H}_{2} \mathrm{SO}_{4}$ for $3 \mathrm{~h}$ at $20^{\circ} \mathrm{C}$, followed by $0.8 \mathrm{M} \mathrm{H}_{2} \mathrm{SO}_{4}$ for $4 \mathrm{~h}$ at $100^{\circ} \mathrm{C}$ (Ausubel et al., 1989; Valiente et al., 1995). The samples were vacuum-dried and washed with $1 \mathrm{~mL}$ methanol and resuspended

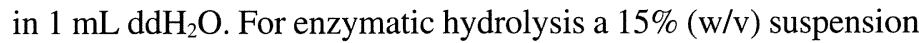
of dried pomace was incubated for $24 \mathrm{~h}$ at $30^{\circ} \mathrm{C}$ with purified commercial Aspergillus niger enzymes (450 U cellulases, $138 \mathrm{U}$ hemicellulases or $0.28 \mathrm{U}$ pectinase [Sigma, St. Louis, MO]). The samples were centrifuged at $12000 \mathrm{rpm}$ for $5 \mathrm{~min}$ and the supernatant filtered through a $0.22 \mu \mathrm{m}$ membrane filter. The HPLC analysis of the different mono- and disaccharides was done with an Aminex HPX087C carbohydrate analysis column.

Isolation and identification of natural occurring micro-organisms

Naturally occurring micro-organisms were isolated from two batches of recently pressed pomace (less than $24 \mathrm{hrs}$ old). A $0.1 \%$ pomace $(\mathrm{w} / \mathrm{v})$ solution was made in sterile $0.85 \%$ saline solution 
and dilutions of $10^{-1}$ to $10^{-8}$ were spread onto agar plates and incubated at $30^{\circ} \mathrm{C}$ for $2 \mathrm{~d}$. Malt extract agar plates (MEA; 3\% malt extract, $0.5 \%$ soy peptone and $1.5 \%$ agar), containing $20 \mu \mathrm{g} / \mathrm{mL}$ chloramphenicol (Roche Biochemicals, Germany) were used to isolate yeast and other fungal species. The yeast isolates were identified by the Centraal Bureau voor Schimmelcultures, The Netherlands.

\section{Screening for hydrolase activity}

The hydrolytic enzyme activities of the various natural isolates were determined as zones produced by the colonies after growth on selective MEA or PCA plates containing cellulose, xylan or starch. Isolates were grown at $30^{\circ} \mathrm{C}$ on $0.1 \%$ carboxymethylcellulose and $0.1 \%$ Birchwood xylan plates (Sigma, St. Louis, MO) until a colony diameter of $5 \mathrm{~mm}$ was obtained. The plates were stained with $0.1 \%$ Congo Red (Teather \& Wood, 1982) to determine cellulase activity, indicated by the presence of a clear zone around the colony. For starch hydrolysis, the isolates were streaked onto MEA or PCA plates containing $0.1 \%$ starch (Merck Biolab Diagnostics, Midrand, SA) and stained with Gram's Iodine after incubation for $24 \mathrm{~h}$ at $30^{\circ} \mathrm{C}$ (Harley \& Prescott, 1993).

Pure cultures were also streaked onto pectin plates $(6.7 \mathrm{~g} / \mathrm{L}$ Yeast Nitrogen Base with amino acids [Difco Laboratories], 1\% glucose, $1 \%$ apple pectin [Sigma, St. Louis, MO], $0.5 \%$ agar and $50 \mathrm{mM}$ phosphate buffer, $\mathrm{pH} 5.5$ ) and incubated at $30^{\circ} \mathrm{C}$ for $10 \mathrm{~d}$ (Cruickshank \& Wade, 1980; Gainvors et al., 1994). The agar surface was flooded with $0.1 \%$ Ruthenium Red (Sigma, St. Louis, $\mathrm{MO}$ ) for $2 \mathrm{~h}$ and destained with several changes of sterile distilled water. Pectin esterases (PE) produce zones with a darker staining than the background, pectin lyases (PL) produce yellow zones or clear zones with yellow margins, and polygalacturonase (PG) activity is indicated as a colourless or pale zone surrounding the colony (Cruickshank \& Wade, 1980).

\section{Microbial hydrolysis of grape pomace}

Yeast isolates that demonstrated enzymatic activity on purified polysaccharides were evaluated for the hydrolysis of the pomace polysaccharides using the different assays discussed below. For all the assays described below, the grape pomace was dried at $60^{\circ} \mathrm{C}$ for $48 \mathrm{~h}$, homogenised with a household coffee grinder and sterilised by ${ }^{60} \mathrm{Co}$ irradiation for $11 \mathrm{~h}$ (sterilisation of the pomace was confirmed on MEA plates).

\section{Plate assays}

A $30 \%(\mathrm{w} / \mathrm{v})$ suspension of the dried and irradiated pomace was further treated at $60^{\circ} \mathrm{C}$ for $2 \mathrm{~h}$ to dissolve any free sugars and centrifuged at $12000 \mathrm{rpm}$ for $5 \mathrm{~min}$. The supernatant was added to an equal volume of $2 \times$ MEA to yield plates with $15 \%(w / v)$ pomace. Yeast isolates were streaked onto these plates and incubated for $24 \mathrm{~h}$ at $30^{\circ} \mathrm{C}$. Enzymatic hydrolysis of pomace was determined using $0.1 \%$ Congo Red as an indicator for cellulose and hemicellulose, Gram's Iodine for starch and $0.1 \%$ Ruthenium Red for pectin.

\section{Liquid assay for extracellular hydrolytic enzymes}

Isolates were inoculated into a $1 \%(\mathrm{w} / \mathrm{v})$ suspension of the dried and irradiated pomace at $1 \times 10^{6}$ cells $/ \mathrm{mL}$ and incubated shaking at $150 \mathrm{rpm}$ for $24 \mathrm{~h}$ at $30^{\circ} \mathrm{C}$. The suspension was centrifuged $(10$ $\min$ at $10000 \mathrm{rpm}$ ) and filtered through $3 \mathrm{MM}$ Whatman paper to remove residual particles. The supernatant was added to fresh pomace to yield a $1 \%(\mathrm{w} / \mathrm{v})$ suspension and incubated aerobically. Samples were taken at different time intervals and the concentration of reducing sugars was determined with the dinitrosalicylic acid (DNS) method (Miller et al., 1960).

\section{Congo Red absorption assays}

Congo Red was used for the colourimetric determination of polysaccharide hydrolysis (Van Rensburg et al., 1997). A suspension of $15 \%(\mathrm{w} / \mathrm{v})$ of the dried and irradiated grape pomace was pretreated for $2 \mathrm{~h}$ at $60^{\circ} \mathrm{C}$ to dissolve any free sugars and inoculated with the respective isolates and incubated aerobically (shaking at $150 \mathrm{rpm}$ ) at $30^{\circ} \mathrm{C}$ for $2 \mathrm{~d}$. The pre-treated pomace was also incubated with purified hydrolases (Sigma, St. Louis, MO), i.e. $1 \mathrm{U}$ cellulase, $5 \mathrm{U}$ hemicellulase, $0.28 \mathrm{U}$ pectinase, $1 \mathrm{U}$ pectin lyase, $30 \mathrm{U}$ amyloglucosidase, a combination of $450 \mathrm{U}$ cellulase and $138 \mathrm{U}$ hemicellulase (all from A. niger), $30 \mathrm{U}$ xylanase (Aureobasidium pullulans), $10 \mathrm{U}$ pectin esterase (orange peel), or $125 \mathrm{U} \alpha$-glucosidase ( $S$. cerevisiae). Samples of $1 \mathrm{~mL}$ were taken at different time intervals, heated at $100^{\circ} \mathrm{C}$ for $15 \mathrm{~min}$ to inactivate the enzymes and cooled to room temperature. To this solution $200 \mu \mathrm{L}$ Congo Red $(100 \mu \mathrm{g} / \mathrm{mL})$ and $800 \mu \mathrm{L} 0.05 \mathrm{mM}$ citrate-phosphate buffer ( $\mathrm{pH}$ 6.2) were added and the absorption of the Congo Red/polysaccharide complex was determined at $540 \mathrm{~nm}$ (Wood et al., 1988); a decrease in colour intensity would indicate hydrolytic activity.

\section{Fermentation of grape pomace}

The $S$. cerevisiae strain Y294 (MAT $\alpha$ leu2-3, 112 ura3-52, his3, trp 1-289) was used as a control for fermentation studies. A $15 \%$ $(\mathrm{w} / \mathrm{v})$ suspension of the dried and irradiated grape pomace was inoculated with either $P$. rhodanensis isolate 1 or $S$. cerevisiae Y294. Where indicated, $1 \mathrm{U}$ of purified cellulase or $0.28 \mathrm{U}$ of pectinase was also added. The cultures were incubated at $30^{\circ} \mathrm{C}$ for $5 \mathrm{~d}$ in small fermentation flasks and hydrolysis of the polysaccharides in the pomace was measured spectrophotometrically using the Congo Red assays as described above. Ethanol production was determined enzymatically with the alcohol dehydrogenase/NADH absorption method (Roche Biochemicals, Germany).

\section{RESULTS AND DISCUSSION}

\section{Acid and enzymatic hydrolysis of grape pomace}

A relatively high concentration of residual glucose was found in the unhydrolysed pomace (Table 1). After acid hydrolysis, a significant increase in the concentrations of glucose and fructose was observed.

Treatment of grape pomace with purified hemicellulase, cellulase or pectinase released small amounts of additional glucose and fructose (Table 1). When all three enzymes were added simultaneously, higher amounts of glucose and fructose were released, indicating that a combination of hydrolytic enzymes is required for the efficient hydrolysis of the polysaccharides in grape pomace. Hydrolysis of the pomace polysaccharides with purified hydrolases was also monitored using the absorption of a Congo Red/polysaccharide complex at $540 \mathrm{~nm}$. As shown in Fig. 1, the purified enzymes were able to hydrolyse the polysaccharide complex to various extents. Approximately $87 \%$ and $76 \%$ of the complex were hydrolysed within $6 \mathrm{~h}$ when either $0.28 \mathrm{U}$ pectinase or a combination of $450 \mathrm{U}$ cellulase and $138 \mathrm{U}$ hemicellulase was added. However, it is important to note that this method does not provide quantitative information on the extent of the hydrolysis, 
TABLE 1

Chemical analysis of sugars (\% w/w dried pomace) released by acid or enzymatic hydrolysis of grape pomace.

\begin{tabular}{lcccc}
\hline & Glucose & Fructose & Mannose & Arabinose \\
\hline Acid hydrolysis & & & & Galactose \\
No hydrolysis & 2.4 & 0.26 & 0.007 & 0.006 \\
Acid hydrolysed & 3.56 & 0.317 & 0.002 & 0.004 \\
& & & & 0.002 \\
Enzymatic hydrolysis & 2.40 & 0.266 & 0.000 & 0.005 \\
No hydrolysis & 2.581 & 0.491 & 0.000 & 0.005 \\
Cellulase (450 U) & 2.743 & 0.613 & 0.000 & 0.005 \\
Hemicellulase (138 U) & 3.024 & 0.448 & 0.000 & 0.009 \\
Pectinase (0.28 U) & & & & 0.000 \\
Cellulase (450 U), & 3.871 & 0.566 & 0.005 & 0.005 \\
hemicellulase (138 U) & & & & 0.005 \\
and pectinase (0.28 U) & & & & \\
\hline
\end{tabular}

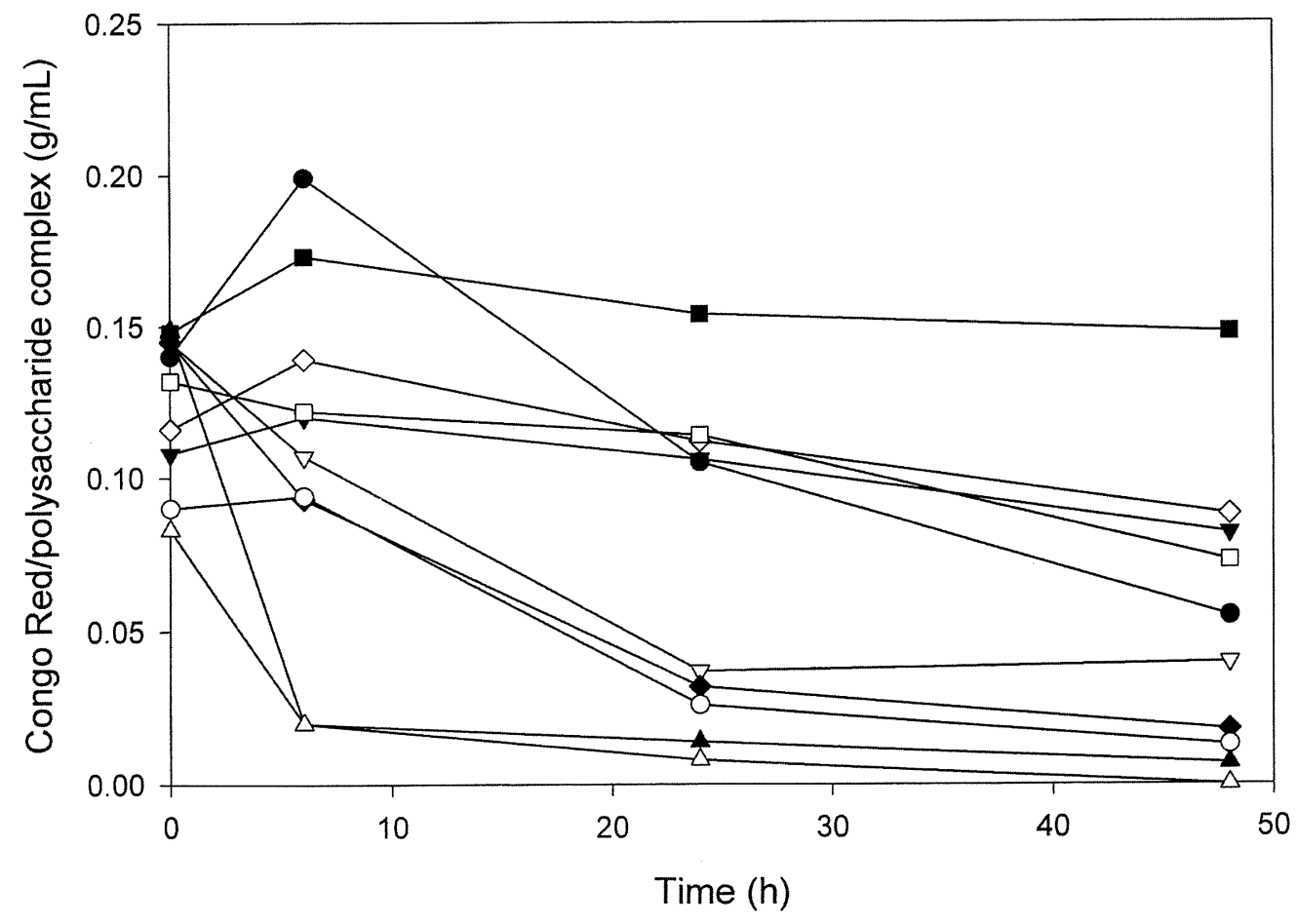

FIGURE 1

Enzymatic hydrolysis of grape pomace with purified commercial enzymes, i.e. (A) $450 \mathrm{U}$ cellulase and $138 \mathrm{U}$ hemicellulase;

$(\nabla) 1 \mathrm{U}$ cellulase; $(\bullet) 5 \mathrm{U}$ hemicellulase; $(\triangle) 0.28 \mathrm{U}$ pectinase; $(\nabla) 10 \mathrm{U}$ pectine esterase; $(\bigcirc) 1 \mathrm{U}$ pectin lyase; $(\bullet) 30 \mathrm{U}$ xylanase;

$(\diamond) 125 \mathrm{U} \alpha$-glucosidase; $(\square) 30 \mathrm{U}$ amyloglucosidase; and $(\square)$ no enzyme added.

i.e. whether the polysaccharides are partially or completely hydrolysed, or the nature and concentration of sugars released.

\section{Isolation and screening of isolates from grape pomace}

Preliminary identification of the grape pomace isolates indicated one actinomycete, 13 yeasts and 14 mycelial fungal isolates (data for 46 bacterial isolates are not shown). Only the actinomycete, nine yeast and three mycelial fungal isolates displayed hydrolytic activities for purified cellulose, hemicellulose, pectin and starch (Table 2). Since the aim of the study was to produce ethanol from the sugars released through hydrolysis of the grape pomace, all subsequent analyses focused on the yeast isolates.
Identification of the nine yeast isolates indicated four different species, i.e. P. rhodanensis, Candida krusei, Kluyveromyces marxianus and a Zygoascus sp.

\section{Microbial hydrolysis of polysaccharide substrates}

The $P$. rhodanensis isolates 1 and 4 (Table 2) were evaluated for the hydrolysis of purified cellulose or grape pomace incorporated into an agar plate (data not shown). The zones observed for the $P$. rhodanensis isolates on cellulose were sigificantly larger than on grape pomace, probably due to the low solubility and inaccessibility of the pomace in the agar. The supernatants containing the extracellular enzymes secreted by the $P$. rhodanensis, $C$. krusei 
TABLE 2

Identification of yeast and mycelial fungi isolated from grape pomace and their ability to degrade purified cellulose (CMC), starch, xylan and pectin: C, Cellulase; X, Xylanase; A, Amylases; PG, Polygalacturonase; PE, Pectin esterase; PL, Pectin lyase.

\begin{tabular}{|c|c|c|c|c|c|c|c|}
\hline Isolate no. & Identification & C & $\mathbf{X}$ & $\mathbf{A}$ & PE & PG & PL \\
\hline \multicolumn{8}{|l|}{ Yeast } \\
\hline 1 & Pichia rhodanensis & +++ & ++ & +++ & - & - & +++ \\
\hline 3 & Pichia rhodanensis & +++ & ++ & +++ & - & - & +++ \\
\hline 4 & Pichia rhodanensis & +++ & ++ & +++ & - & - & +++ \\
\hline 6 & Pichia rhodanensis & +++ & ++ & +++ & - & - & +++ \\
\hline 2 & Candida krusei & + & + & ++ & ++++ & - & ++ \\
\hline 5 & Candida krusei & + & + & ++ & ++++ & - & ++ \\
\hline 8 & Candida krusei & + & + & ++ & ++++ & - & ++ \\
\hline 7 & Kluyveromyces marxianus & ++ & + & + & - & + & ++ \\
\hline 9 & Zygoascus sp. & + & + & ++ & + & ++++ & - \\
\hline \multicolumn{8}{|c|}{ Mycelial Fungi and Actinomycetes } \\
\hline Mucor sp. & ++ & +++ & ++ & ++++ & ++++ & - & \\
\hline Penicillium sp. & +++ & +++ & +++ & - & - & - & \\
\hline Aspergillus sp. & ++++ & ++++ & ++++ & - & ++++ & ++++ & \\
\hline Streptomyces sp. & +++ & +++ & +++ & - & - & - & \\
\hline
\end{tabular}

$(+)$, clear zones produced; $(-)$, no clear zones produced.

Results for bacterial isolates are not shown.

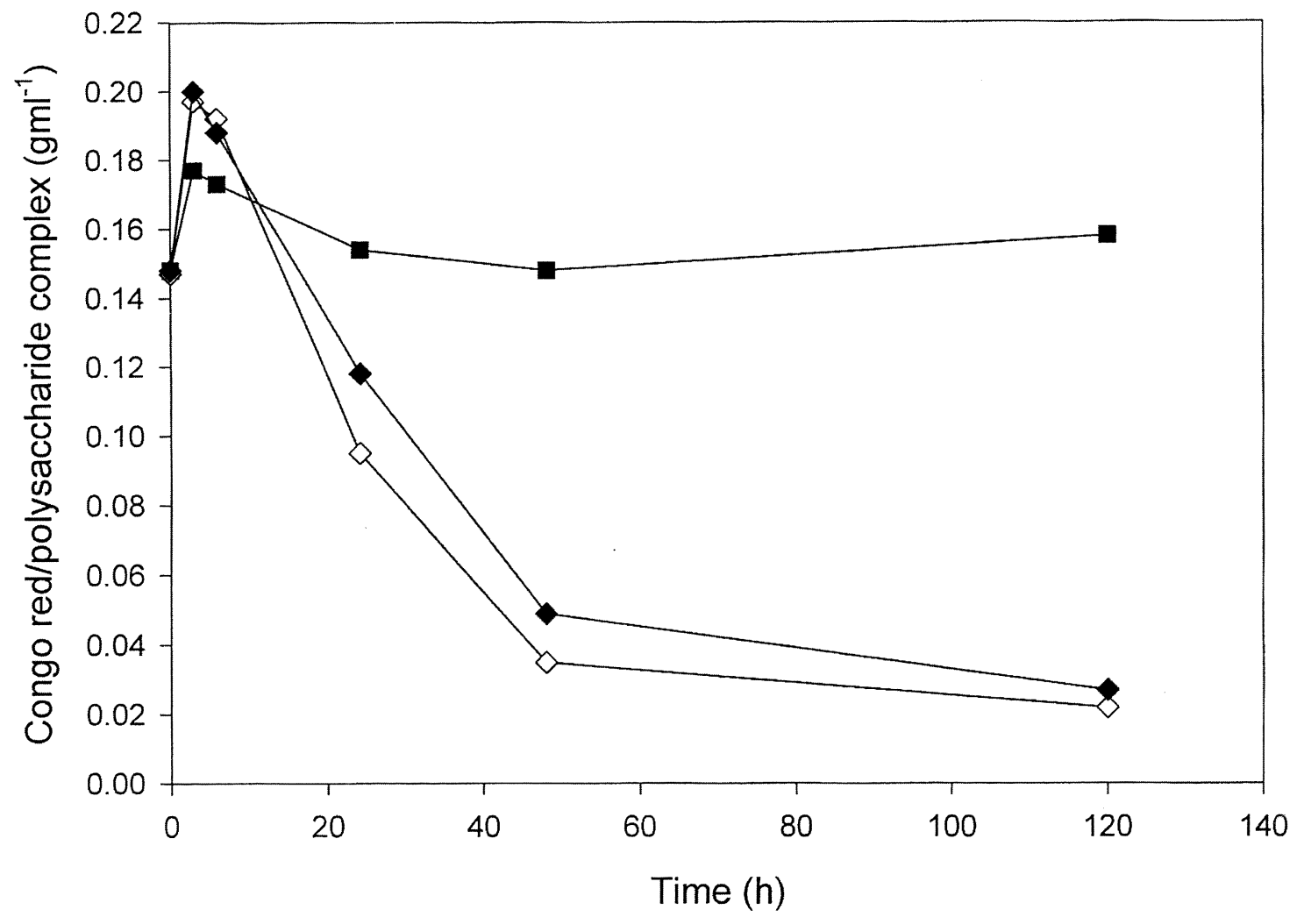

FIGURE 2

Microbial hydrolysis of pomace polysaccharides by $P$. rhodanensis isolate $1(\diamond)$ and isolate $4(\diamond)$ under aerobic conditions. The negative control ( $\mathbf{\square})$ had no inoculum. 
TABLE 3

Levels of reducing sugars after treatment of pomace with supernatant from isolates.

\begin{tabular}{|c|c|c|c|c|}
\hline \multirow[t]{2}{*}{ Inoculum } & \multicolumn{4}{|c|}{$\%$ Reducing sugars (w/w dry pomace) } \\
\hline & Time $_{(\mathrm{h})}$ & $\mathrm{T}_{0}$ & $\mathrm{~T}_{3}$ & $\mathrm{~T}_{6}$ \\
\hline P. rhodanensis & & 0.069 & 0.242 & 0.279 \\
\hline C. krusei & & 0.063 & 0.270 & 0.250 \\
\hline Zygoascus sp. & & 0.060 & 0.263 & 0.254 \\
\hline
\end{tabular}

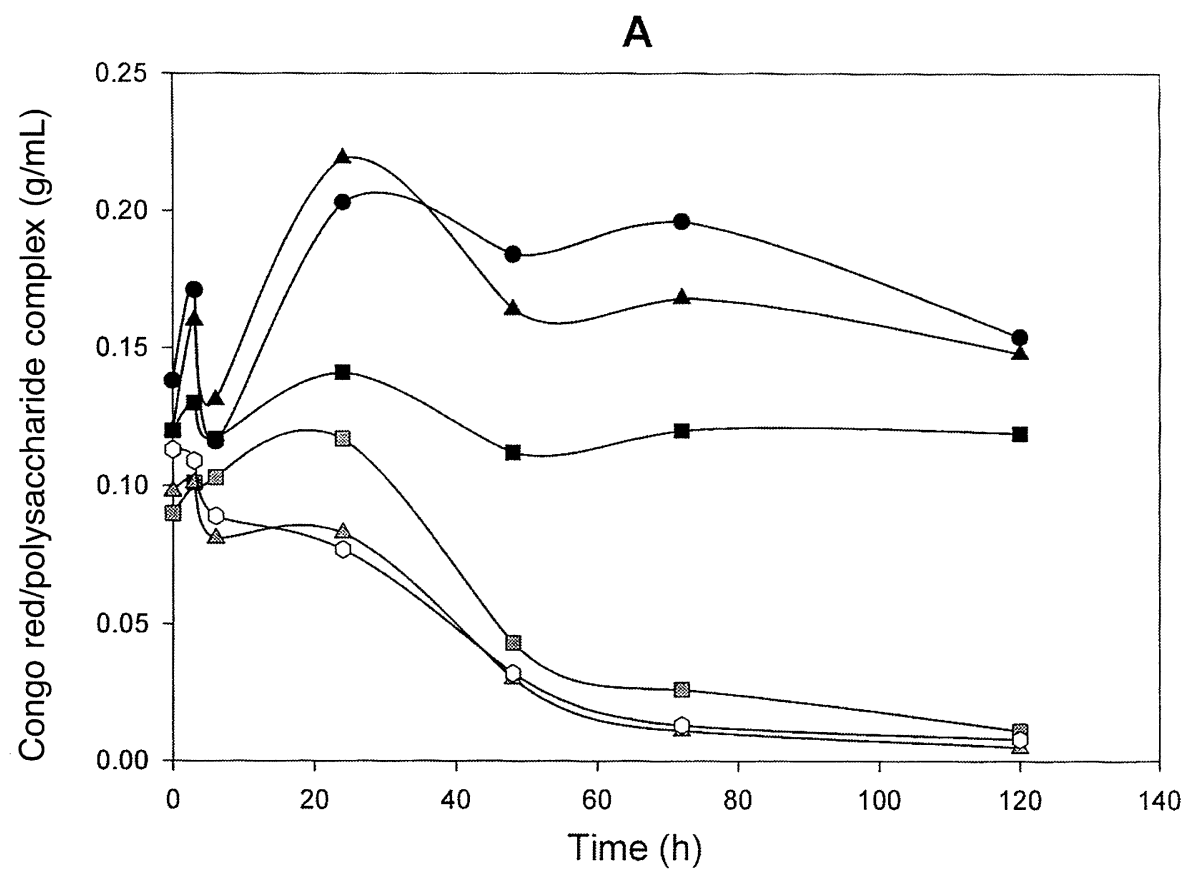

B

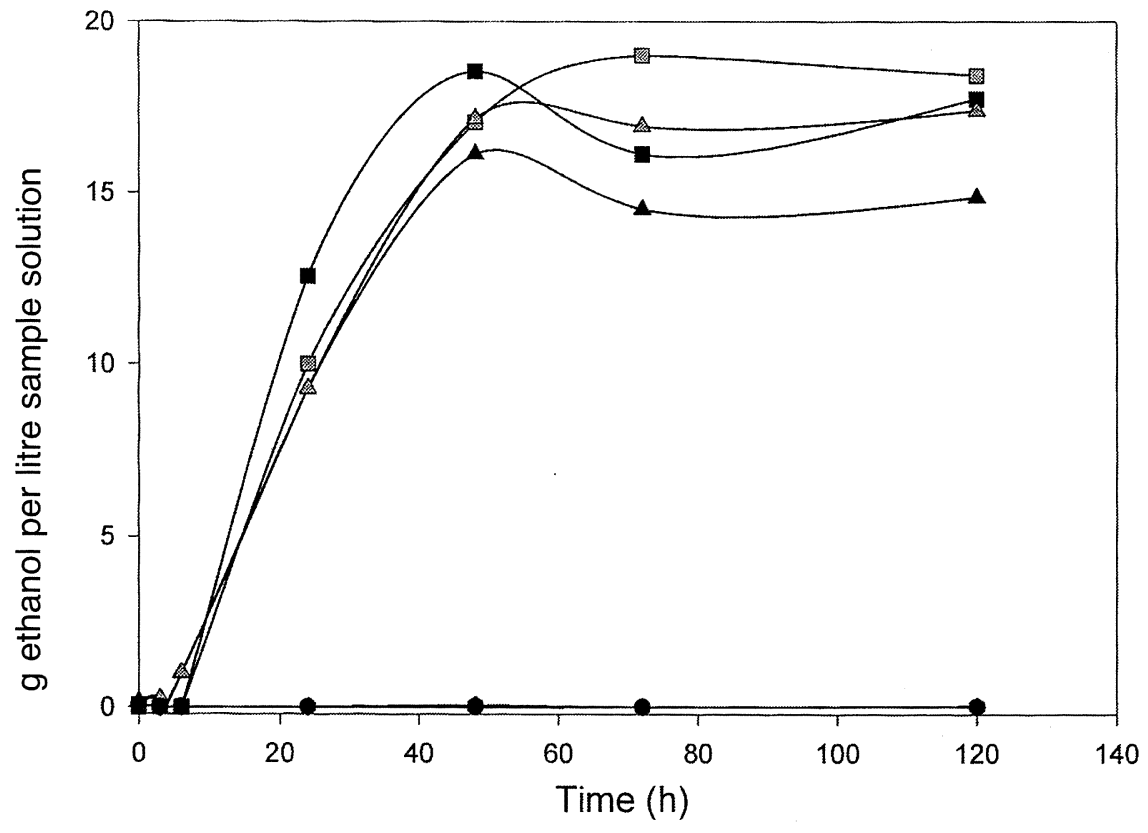

FIGURE 3

(A) Microbial hydrolysis of pomace polysaccharides under anaerobic conditions and (B) ethanol production by P. rhodanensis and

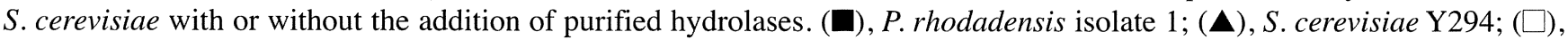
$P$. rhodadensis isolate 1 with cellulase and pectinase; $(\triangle), S$. cerevisiae Y294 with cellulase and pectinase; $(\mathbf{O})$, only cellulase and pectinase; $(\diamond)$, no inoculum. (Please note that the latter two overlap in (B)). 
and Zygoascus isolates were subsequently used to evaluate the organisms' ability to hydrolyse a pomace suspension. A sharp increase in reducing sugars was observed within $3 \mathrm{~h}$ for all three isolates (Table 3 ), suggesting hydrolysis of the pomace polysaccharides by the extracellular enzymes. However, when compared to the amounts of sugars released by acid hydrolysis (Table 1), it is clear that the enzymatic hydrolysis was far from complete. After prolonged incubation under aerobic conditions $(48 \mathrm{~h})$, the Congo Red absorption assay (Fig. 2) indicated that $P$. rhodanensis isolates 1 and 4 hydrolysed $76 \%$ and $67 \%$ of the complex, respectively.

Since we were interested in the yeast strains' ability to hydrolyse the pomace polysaccharides and also ferment the sugars, the strains were evaluated in a $15 \%$ pomace supsension under fermentative conditions. As determined by the hydrolysis of the Congo Red/polysaccharide complex, $P$. rhodanensis isolate 1 was not very effective under anaerobic conditions, albeit more efficient that S. cerevisiae Y294 (Fig. 3). However, both P. rhodanensis isolate 1 and $S$. cerevisiae Y294 were able to effectively ferment the residual sugars in the pomace to ethanol, yielding $18.5 \mathrm{~g} / \mathrm{L}$ and $16.1 \mathrm{~g} / \mathrm{L}$ ethanol after $48 \mathrm{~h}$, respectively. As expected, the addition of cellulase and pectinase hydrolysed the pomace more effectively, with approximately $90 \%$ of the complex hydrolysed after $72 \mathrm{~h}$. However, the addition of cellulase and pectinase together with $S$. cerevisiae or $P$. rhodanensis isolate 1 , increased the ethanol yield only slightly. These results suggest that the sugars released by the hydrolases did not contribute significantly towards the production of ethanol within the first two days of fermentation.

\section{CONCLUSIONS}

The relative amounts of different polysaccharides in grape pomace greatly influence the efficacy of micro-organisms to hydrolyse the substrates, as well as the type and levels of fermentable sugars that are released. Chemical analysis showed relatively high concentrations of residual glucose and fructose in the unhydrolysed pomace, with even more fermentable sugars being released through acid hydrolysis. Fermentation of these residual sugars can increase the economic value of grape pomace by providing an additional source of grape-based ethanol (wine spirits). Hydrolysis of the complex polysaccharides into more digestible sugars can also improve its nutritional value and render it more suitable as an animal feed.

Although treatment of grape pomace with purified hemicellulase, cellulase and/or pectinase released additional monosaccharides from the grape pomace, the addition of purified enzymes to grape pomace would probably not be cost effective for commercial purposes. The best alternative would be to utilise a yeast that is able to both hydrolyse the polysaccharides in grape pomace and ferment the sugars to ethanol. Although promising results have been obtained with the $P$. rhodanensis isolate, further investigation is required to evaluate its commercial applicability for the hydrolysis of pomace.
An important finding of this study was the ability of $P$. rhodanensis isolate 1 and $S$. cerevisiae Y294 to produce significant levels of ethanol from the residual sugars in the unhydrolysed pomace. It therefore seems possible that the commercial value of grape pomace could be greatly enhanced by direct fermentation of the pomace following a mild heat treatment to dissolve the residual sugars. Furthermore, the ethanol yield could further be increased by employing a strong fermenting yeast, e.g. a commercial wine yeast. If this could be combined with a wild type or recombinant yeast strain expressing the essential hydrolytic enzymes, the ethanol yield may be increased even further.

\section{LITERATURE CITED}

Amerine, M.A., Berg, H.W. \& Cruess, W.V., 1972 (3rd ed). Technology of wine making. AVI Publishing Company, Connecticut.

Ausubel, F.M., Brent, R., Kingston, R.E., Moore, D.D., Seidman, J.G., Smith, J.A. \& Struhl, K., 1989. 1989. Current Protocols in Molecular Biology. John Wiley and Sons, New York.

Cruickshank, R.H. \& Wade, G.C., 1980. Detection of pectic enzymes in pectinacrylamide gels. Anal. Biochem. 107, 177-181.

Gainvors, A., Frézier, V., Lemaresquir, H., Lequart, C., Aigle, M. \& Belarbi, A., 1994. Detection of polygalacturonase, pectin-lyase and pectin-esterase activities in Saccharomyces cerevisiae strain. Yeast 10, 1311-1319.

Glazer A.N., \& Nikaido, H., 1995. Microbial Biotechnology. W.H. Freeman and Company, New York.

Greene, S., 1998. Recycling in the wine industry. Wynboer, April 1998, 56-57.

Hang, Y.D., 1988. Recovery of food ingredients from grape pomace. Process Biochem. 23, 2-4.

Harley, J.P. \& Prescott, L.M., 1993. Laboratory Exercises in Microbiology, 2nd edition. Wm. C. Brown Publishers, Iowa.

Heimoff, S., 1996. The green practices of winery and vineyard waste. In: Wine Business Monthly, March 1996.

Hulme, A.C., 1970. The Biochemistry of Fruits and their Products, Vol. 1. New York Academic Press.

Mazza, G., 1995. Anthocyanins in grapes and grape products. Crit. Rev. Food Science and Nutrition 35, 341-371.

Miller, G.L., Blum, R., Glenno, W.E. \& Burton, A.L., 1960. Measurement of carboxymethylcellulose activity. Anal. Biochem. 2, 127-132.

Petersen, S.H., Van Zyl, W.H. \& Pretorius, I.S., 1998. Development of a polysaccharide degrading strain of Saccharomyces cerevisiae. Biotechnology Technique $12,615-619$.

Prescott, L.M., Harley, J.P. \& Klein, D.A., 1993 (2nd ed). Microbiology. Wm. C. Brown Publishers, Iowa.

Teather, R.M., \& Wood, P.J., 1982. Use of congo red-polysaccharide interactions in enumeration and characterisation of cellulolytic bacteria from bovine rumen. Appl. Environ. Microbiol. 43, 777-780.

Valiente, C., Arrigoni, E.R., Esteban, M. \& Amado, R., 1995. Grape pomace as a potential food fiber. J. Food Science 60, 818-820.

Van Rensburg, P., Van Zyl, W.H. \& Pretorius, I.S., 1997. Over-expression of the Saccharomyces cerevisiae exo- $\beta$-1,3-glucanase gene together with the Bacillus subtilis endo- $\beta$-1,3-1,4-glucanase gene and the Butyrivibrio fibrisolvens endo- $\beta$ 1,4-glucanase gene in yeast. J. Biotech. 55, 43-53.

Van Rensburg, P., Van Zyl, W.H. \& Pretorius, I.S., 1998. Engineering yeast for efficient cellulose degradation. Yeast 14, 67-76.

Wood, T.M., McCrae, S.I., Wilson, C.A., Bhat, K M. \& Gow, L.A., 1988. Aerobic and anaerobic fungal cellulases, with special reference to their mode of attack on crystalline cellulose. In: Aubert, J.-P., Beguin, P. \& Millet J. (eds). Biochemistry and Genetics of Cellulose Degradation. Academic Press, London. pp. 31-52. 